\title{
Research on the Contents of Teaching Evaluation in Colleges and Universities Based on Grounded Theory and Students' Perspective
}

\author{
Zhijun Yin \\ Department of Engineering Management, \\ School of Economics and Management, \\ Hebei University of Technology \\ Tianjin, China \\ E-mail: yinzhijun2006@126.com
}

\author{
Yaling Dong * \\ Department of Engineering Management, \\ School of Economics and Management, \\ Hebei University of Technology \\ Tianjin, China \\ E-mail: dongyaling262@163.com
}

\begin{abstract}
Student evaluation of teaching effectiveness is a teaching evaluation method that gradually applied in colleges and universities at both home and abroad. However, there are various problems in the process including subjective rating, limited evaluation content and results in inaccuracy. In accordance with the qualitative research on grounded theory, this research mainly conducts the study from the proposition of student. Through interviews with 35 students and coding in three phases, this research found that teachers' ethics and introduction after class are also significant content that students concern about in addition to the existing teaching evaluation dimension. Therefore, that's to say, the non-teaching factor has so great effect on the result of the evaluation of teaching quality that needs more attention of teachers.
\end{abstract}

Keywords-grounded theory; student perspective; student evaluation; non-teaching factors

\section{INTRODUCTION}

Chinese colleges and universities began to introduce students' evaluation of teaching from the Mid-1980s and were on the right track in the 1990s. After more than 30 years of development, student evaluation has become an important part of the teaching activities of colleges and universities. This measure is essential for teachers to improve teaching and the efficient learning of students. However, the researchers pointed out that students' evaluation of teaching is influenced by many aspects such as "self-interest", "subjective cognition" and "teacher-student relationship" [1]; the distortion of evaluation information leads to the phenomenon that the evaluation results cannot reflect the true teaching level and actuality of teachers[2]. Teachers pay much attention to the score and reduce the requirements for students, which result in a significant reduction in the quality of teaching [3]. The problem makes this method fall into difficulties. How to improve the effectiveness of this method has become an urgent problem.

The Ministry of Education's second batch of industry-university cooperation and education projects in 2018 (201802132024);

2018 Hebei University of Technology undergraduate quality curriculum construction project (YK2018065).

Research and Practice Project on Teaching Reform of Innovation and Entrepreneurship Education in Hebei Higher Education Institutions "Design of Teaching Content System Based on Systematic Theory of Work Process" (Project No.: 2017CXCY193)
In view of the shortcomings in the evaluation, Chinese scholars have tried to find reasons and make suggestions from multiple angles and dimensions recently. Based on the theory of information asymmetry, Jiliang Zhou used questionnaires and interviews to explore the reasons for the unscientific operation of evaluation teaching [2], and then used empirical research methods to analyze the behavioral bias of colleges and universities from the perspective of university management system [3]; Minmei He, Jingjing Yang pointed out the lack of existing evaluation indicators through a questionnaire survey, and proposed the students to participate in the construction of evaluation indicators [4]; Youqing Chen reflected deeply through the three typical evaluation indicators, and put forward the design idea of "teaching evaluation by teaching" [5]. Tongjian Zhou analyzed the ethical dilemmas of "teaching", "learning and evaluating" faced by students' evaluation of teaching from a moral point of view and proposed countermeasures from the concept of teaching and the implementation process [6]. The existing researches have done a lot of works and achieved fruitful results. However, there are still two shortcomings: First, it lacks the validity and representativeness of the existing indicators from the perspective of students, The factors influenced the evaluation of teaching are not explored in-depth, and the methods are not given in a targeted manner. Second, they have mostly used questionnaires. The questionnaire has problems such as limited questions and fixed dimensions, which makes the research results not fully reflect the actual situation.

More and more mainstream scholars believe that grounded theory is very suitable for analyzing Chinese problems [7]. The essence of the grounded theory is to use the qualitative method to construct the theory [8]. Getting the research questions from the interviewer's point of view, and then give corresponding suggestions and countermeasures. The grounded theory can be used to explore the unexpected problems of the researchers, and even discover new research points, which effectively compensates for the deviations and commonalities of the traditional questionnaires due to factors such as "dimensional limitations, incomplete design, and unscientific distribution methods". Therefore, with the theory of grounded theory, this paper studies students' understanding of evaluation from the 
perspective of students and combines quantitative analysis methods to further explore the content and influencing factors of evaluation.

\section{RESEARCH IDEAS AND METHODS}

The ideas and methods in this paper are shown in Fig. 1, which is divided into five stages.

In the first phase, the research direction is determined by extensive reading of the literature. In the second stage, interviewees were selected and in-depth interviews were conducted. The third stage is data coding. The fourth stage verifies whether the core code is saturated. The fifth stage performs frequency statistics on the identified core categories.

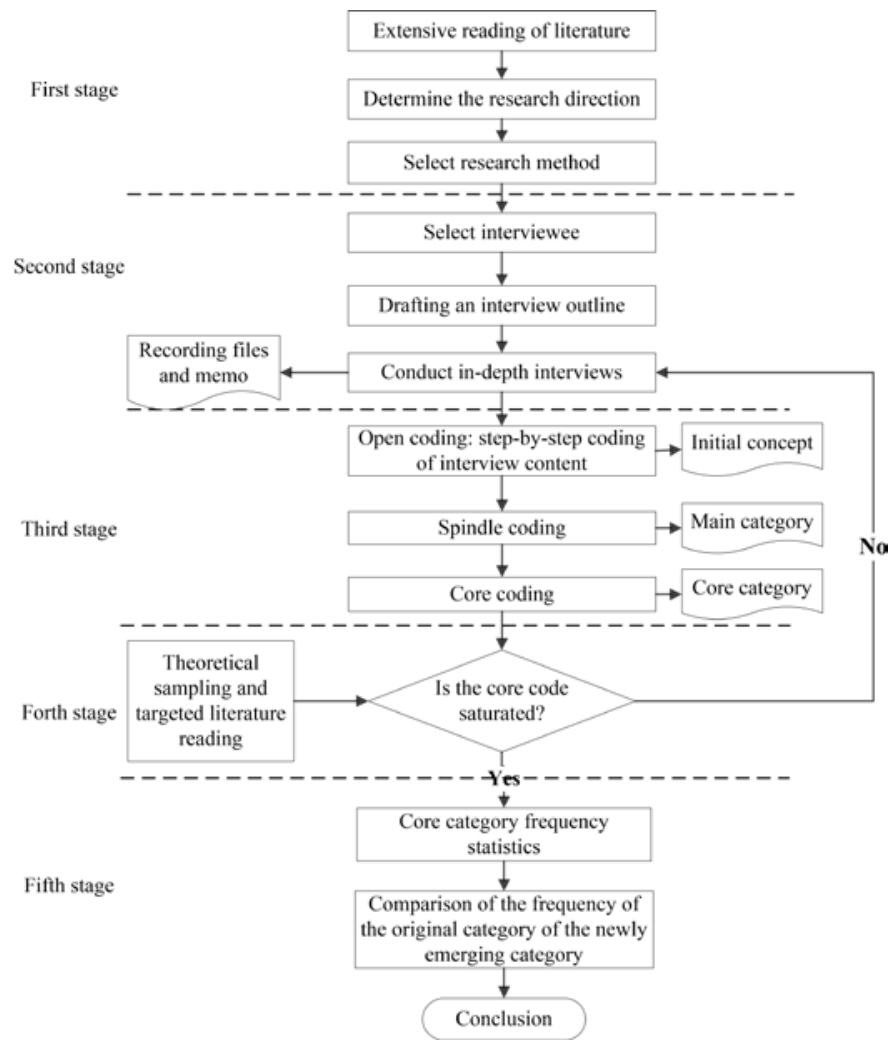

Fig. 1. Research flow chart

\section{The Research Process and Results}

\section{A. Interview}

In this study, two colleges-"Hebei University of Technology" and "Hebei University" were selected as the sample institutions. 35 students from different grades, majors and different levels of learning were selected as interviewees. The background of the respondents is shown in Table I. In order to make the respondents fully prepared, they will express more relevant information during the interview. The author had sent the interview outline to them one day in advance. During the interview, the respondents were encouraged to speak freely with an open mind, and the author did not express relevant opinions. Considering the interviewee had different personalities and different interview environments, each interview time ranged from 10-20 minutes, and the average is 12 minutes.

It can be seen from Table I that the number of respondents in individual backgrounds such as gender, grade, ranking, and major is no more than five. Therefore, it can be considered that the respondents can effectively represent the research subject.

TABLE I. LIST OF BACKGROUNDS OF RESPONDENTS

\begin{tabular}{|c|c|c|c|}
\hline Background & Feature & Number & Proportion(\%) \\
\hline \multirow{3}{*}{ Gender } & Male & 20 & 57.1 \\
\cline { 2 - 4 } & Female & 15 & 42.9 \\
\hline \multirow{3}{*}{ Grade } & First grade & 8 & 22.9 \\
\cline { 2 - 4 } & Second grade & 11 & 31.4 \\
\cline { 2 - 4 } & Third grade & 9 & 25.7 \\
\cline { 2 - 4 } & Fourth grade & 7 & 20.0 \\
\hline \multirow{3}{*}{ Subjet } & Upper-middle & 15 & 45.7 \\
\cline { 2 - 4 } & Middle & 10 & 25.7 \\
\cline { 2 - 4 } & Lower-middle & 10 & 28.6 \\
\cline { 2 - 4 } & Humanities & 13 & 37.1 \\
\cline { 2 - 4 } & Social science & 10 & 28.6 \\
\cline { 2 - 4 } & Science and engineering & 12 & 34.3 \\
\hline
\end{tabular}

\section{B. Data encoding}

\section{1) Open coding}

After the interview, the recordings were converted into words in a timely manner, totaling 21,630 words. The text information is coded line by line, forming a memo of about 5,000 words. For example: "The class of Consumer Behavior is very unique. When the teacher talked about beer, she bought a few bottles of beer, and let us taste... many times. Like this, when learning something, we could take the physical object out" is coded as " practicality ".

There are 36 first-level codes for "types of teachers that students like and dislike" and 18 first-level codes for "attitudes of students towards evaluation".

\section{2) Spindle coding}

After the open coding, the first-level coding is repeatedly compared and summarized, the concept or category with the type of group is searched, and the correlation between the concepts is carefully analyzed, judged, re-integrated and classified. During this period, relevant categories began to emerge. Combining codes that reflect common concepts, for example, "teachers prepare lessons before class" and "respecting students' ideas" are coded as "teaching attitudes"; "new teaching processes" and "class is relaxing" is classified as "teaching method".

There are 13 secondary codes for the "types of teachers that students like and dislike" and 6 secondary codes for" attitudes of students towards evaluation ".

\section{3) Core Coding}

In the core coding (selective coding) phase, select the core categories that can influence the results of the evaluation. The selection of the core categories strictly follows the principles: First, this category can occupy a core position. Second, after continuous comparison and analysis, the concept is sufficiently representative. Third, the number of occurrences is frequent enough. Fourth, the selection of the core category is abstract. Among the "factors, seven core categories related to the 
teacher's teaching" and four core categories of students' "learning", Showed in Table II. The five categories of "teaching attitude, teaching content, teaching schedule, teaching method and teaching effect" in the core categories related to teachers' "teaching" have been reflected in the existing research results, while "extracurricular tutoring, teacher's morality” indicators are new categories discovered through this study.

The purpose of this study is to use the grounded theory to conduct evaluation and exploration, so it does not abandon some core categories that are frequently but cannot be classified as "teachers" or "student". We classify them as "positive factors" and "negative factors", showed in Table III.

TABLE II. CORE CODING RESULTS

\begin{tabular}{|c|c|}
\hline Main part & Core category \\
\hline $\begin{array}{c}\text { Teachers' } \\
\text { “teaching” }\end{array}$ & $\begin{array}{c}\text { Teaching attitudes; teaching content; teaching } \\
\text { schedule; teaching method; teaching effect; } \\
\text { extracurricular tutoring; teacher's morality }\end{array}$ \\
\hline $\begin{array}{c}\text { Student's } \\
\text { learning }\end{array}$ & $\begin{array}{c}\text { Learning target; learning passion; acquire } \\
\text { knowledge; gain the practical ability }\end{array}$ \\
\hline
\end{tabular}

TABLE III. “POSITIVE FACTORS” AND “NEGATIVE FACTORS” AFFECTING THE EVALUATION

\begin{tabular}{|c|c|}
\hline Contend & Core Coding \\
\hline Positive factors & $\begin{array}{c}\text { Teachers have personality; teacher's image is } \\
\text { good; the teacher's character is good; more } \\
\text { exchanges between teachers and students; } \\
\text { interested in the discipline }\end{array}$ \\
\hline $\begin{array}{c}\text { Negative } \\
\text { factors }\end{array}$ & $\begin{array}{c}\text { Task-based evaluation; unclear understanding } \\
\text { of evaluation; don't dare to comment; personal } \\
\text { sentiment }\end{array}$ \\
\hline
\end{tabular}

\section{Theoretical sampling}

Based on the available data, theoretical sampling is used to verify whether the existing core categories are saturated. Based on the experience of previous researchers, this interview was conducted in the form of a small discussion. 10 different background characteristics' students were re-selected, and two small-scale seminars of five people were held. At the symposium, the author asked questions according to the interview outline. The entire process is recorded, and the above data recording and the encoding process are repeated again. The core categories formed by the interview were compared with the core categories formed by the initial interviews. The results were all attributed to the existing categories and did not complement, so there is a reason to believe that the core categories are saturated.

\section{Quantitative analysis of core categories}

1) Quantitative analysis of core categories of "teaching" aspects

The statistics of the frequency of each core category in the "teaching" aspect are shown in Table IV

It can be seen from in Table IV that the frequency of "teacher morality" is slightly lower than the original five existing indicators, but the difference is few, but the frequency of "extracurricular tutoring" is significantly lower than the other six indexes.

As can be seen, students pay much attention to the three dimensions "teaching attitude, teaching content, and teaching schedule", followed by "teaching methods" and "teaching effects", and finally "teachers' morality" and "extracurricular tutoring". And, it is clearly researched that the students in lower grades, intermediate grades, and science and engineering disciplines pay more attention to teachers' " extracurricular tutoring ". The other six indicators have little difference among the students of different backgrounds.

2) Quantitative analysis of each core category of "learning" aspects

It can be seen from TableV that the respondents value the proportion of the two indicators of "learning enthusiasm" and "learning knowledge", while the proportions of "learning goals" and "practical ability" are small.

TABLE IV. “TEACHING” ASPECTS OF THE FREQUENCY STATISTICS TABLE FOR EACH CORE CATEGORY

\begin{tabular}{|c|c|c|c|c|c|c|}
\hline $\begin{array}{c}\text { Core } \\
\text { category }\end{array}$ & $\begin{array}{c}\text { Teaching } \\
\text { attitudes }\end{array}$ & $\begin{array}{c}\text { Teaching } \\
\text { content }\end{array}$ & $\begin{array}{c}\text { Teaching } \\
\text { schedule }\end{array}$ & $\begin{array}{c}\text { Teaching } \\
\text { method }\end{array}$ & $\begin{array}{c}\text { Teaching } \\
\text { effect }\end{array}$ & $\begin{array}{c}\text { Extracurricular } \\
\text { tutoring }\end{array}$ \\
\hline Frequency & 30 & 31 & 33 & 29 & 28 & \\
moacher's & 16 & 23 \\
\hline
\end{tabular}

TABLE V. FREQUENCY STATISTICS OF INTERVIEWEES' ATTENTION TO EACH CORE CATEGORY (\%)

\begin{tabular}{|l|c|c|c|c|}
\hline Core category & $\begin{array}{c}\text { Learning } \\
\text { goals }\end{array}$ & $\begin{array}{c}\text { Learning } \\
\text { enthusiasm }\end{array}$ & $\begin{array}{c}\text { Learning } \\
\text { knowledge }\end{array}$ & $\begin{array}{c}\text { Practical } \\
\text { ability }\end{array}$ \\
\hline Proportion(\%) & 48.5 & 80.0 & 74.3 & 57.1 \\
\hline
\end{tabular}

\section{CONCLUSIONS}

\section{A. New indicators should be included in the evaluation}

Through the coding and statistics of interview data, we find that students hope to learn not only knowledge but also the truth and noble morality of the people. So the "teachers' morality" is also necessary to be included in the teaching evaluation indicators.
Students of different grades and academic performances have inconsistent ties to teachers. The students in the lower grades are in the state of exploration for university life and study, hoping to have more professional exchanges with teachers; students with grades at the upper-middle level hope to explore more academic issues with teachers. Therefore, "extracurricular tutoring" has become an indicator for these students to evaluate the teaching level of teachers. It is 
necessary to set and use this indicator reasonably in the evaluation system.

The study also found that students often measure the quality of teachers' teaching based on whether they have "learning enthusiasm" and "learning knowledge". Therefore, teachers must also consider using effective teaching methods to stimulate students' enthusiasm for learning, promote students' interest in the subject, and learn more.

\section{B. Teachers should fully consider the impact of non-teaching factors}

The study found that there are some non-teaching factors that also have a positive or negative impact on the results of student evaluation. However, most of these factors are based on the students' emotions or the personality of the teachers. They do not reflect the actual teaching level and should not be used as an indicator to evaluate the quality of teachers' teaching.

However, in practice, these factors affect the students' evaluation of teachers. Therefore, teachers need to enhance the role of positive factors and avoid the influence of negative factors.

\section{INSUFFICIENCY AND PROSPECTS OF THE RESEARCH}

The Ministry of Education clearly put forward instructions for undergraduates to increase their burdens, and it is of great significance to improve the quality of undergraduate teaching. Most colleges and universities use the results of student evaluation as a criterion for evaluating teachers and improving teaching. From the perspective of university education, it is the key to promote the development of higher education for students to play their due role. Therefore, it is of great significance to improve the evaluation indicators and improve the evaluation methods so that the evaluation can fully exert its surface and deep, short-term and long-term effects.
This study uses grounded theory to find out that nonteaching factors will have an impact on teaching evaluation results, which may cause many colleges and universities to evaluate the results of teaching and deviating from the real situation. However, the shortcoming is that it only proposes measures from the evaluation results to reduce the influence of non-teaching factors. However, how to fundamentally let students accept evaluation, objective and true participation in evaluation, and let them truly play their due role is the key to future scholars' research.

\section{REFERENCES}

[1] Pinpin Wang. "Reflection on the 'Student-centered' classroom teaching quality evaluation thought”, Journal of Higher Education Research, vol.41, pp.96-99+115, Sep.2018.(In Chinese)

[2] Jiliang Zhou.”A New Explanation of Decoding the Problem of College Students' Evaluation of Teaching-Based on the Information Asymmetry Theory”, Educational Science, vol.26, pp.30-38, Dec.2018.(In Chinese)

[3] Jiliang Zhou. An Empirical Study on the Influencing Factors of College Students' Evaluation of Teaching Deviation-Based on the Perspective of Institutional Analysis, Higher Education Research, vol.26, pp. 59-72, Feb.2018.(In Chinese)

[4] Minmei He, Jingjing Yang, Jing Zhao. "Analysis of the Effect of Students' Evaluation of Teaching in Colleges and Universities” Chinese Medicine Education, vol.36, pp. 16-19+26, Oct.2017.(In Chinese)

[5] Youqing Chen, Tao Tao. "Design of Evaluation Index for Classroom Teaching Based on Teaching Evaluation”, Courses . Teaching Materials. Teaching Methods, vol.36, pp. 45-52, 2016. (In Chinese)

[6] Tongjian Zhou. Ethical Dilemma and Countermeasures of Students' Evaluation of Teaching in Domestic Universities, Heilongjiang Higher Education Research, vol.34, pp. 100-103, Apr.2018.(In Chinese)

[7] Shuying Xu, Zhongming Liu. "Frontier Research on Chinese Enterprise Management”, Beijing: Peking University Press, 2016. (In Chinese)

[8] Azhar S M, Shahid A. Sketching effective faculty professional development framework, Asian Journal of Business Management, vol.6, pp. 59-72, 2014. 